\title{
Impact of caring for people living with HIV on the psychosocial well-being of palliative caregivers
}

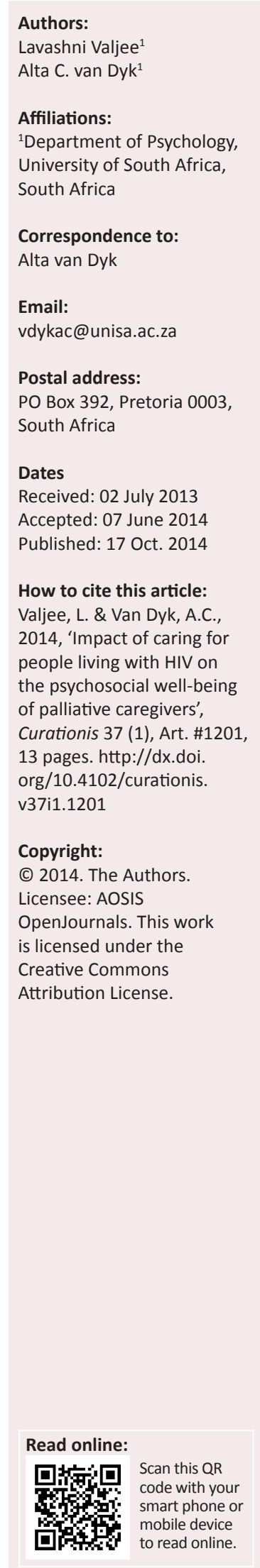

Acquired immunodeficiency syndrome (AIDS) continues to be a serious public health issue, and it is often the caregivers who carry the brunt of the epidemic. Caregivers of people with AIDS face distinctive demands that could make them more prone to occupational stress, with serious consequences for their psychosocial well-being. The impact of caring for people living with HIV infection on the psychosocial well-being of palliative caregivers was investigated using in-depth interviews and questionnaires in 28 participants. The results indicated no burnout, but occupational stress was prevalent. Factors impacting negatively on well-being were stressors inherent in AIDS care, such as suffering and dying of the persons being cared for, work-related stressors such as heavy workload, lack of support and ineffective coping mechanisms. Positive aspects of caring such as job satisfaction, holistic palliative care, effective coping mechanisms and psychosocial support were identified. Recommendations to curb the negative effects of caregiving are provided.

\section{Introduction}

The advent of AIDS has given new meaning to caregiving for healthcare workers in South Africa. This new meaning could be due to the multifaceted nature of the disease (which involves medical care, physical care, psychological, social and spiritual aspects) as well as the comprehensive and holistic type of care that is needed for people living with HIV (Delobelle et al. 2009). AIDS care presents a significant burden for those caring for people infected with and/or affected by HIV, and coping with the disease that has fallen onto caregivers. Furthermore, AIDS has become a manageable disease with the introduction of antiretroviral therapy (ART) which, counterintuitively, often places additional demands on health delivery systems due to the complications often associated with medication and opportunistic diseases that could prevail (Mullins 2009).

ART often requires adherence to complex medication regimens which are frequently associated with adverse side-effects, which can affect a patient's motivation to adhere to their medications (Miller et al. 2007). Patients may also encounter ongoing health problems despite the treatment (for example, the side-effects of being on medication, such as an upset stomach, liver and kidney problems, rashes, bleeding problems), which often render them more dependent on healthcare workers (Miller et al. 2007; Joint United Nations Programme on HIV / AIDS [UNAIDS] 2006). This could create psychological problems such as depression, anxiety, helplessness and vulnerability in both patients and caregivers (Miller et al. 2007). Healthcare workers may be vulnerable to factors such as caregiver burden, occupational stress and burnout, depression, anxiety and decreased psychological functioning, which can result in psychological distress and decrease their ability to care for others (Fransman et al. 2000; Maslach, Jackson \& Leiter 1986).

Few studies in sub-Saharan Africa have investigated the factors related to the mental health, psychosocial well-being and needs of caregivers working in AIDS care (Davids et al. 2009). Research in this area is especially crucial in countries where the brunt of care for people living with HIV is taken on by caregivers. Caring for people with serious chronic illness is a physical and emotional challenge for even the most committed of caregivers, and can have detrimental effects on well-being if not managed effectively (Mullins 2009). There is a need for research focusing on the psychosocial needs of caregivers as well as a further need to recognise the negative impact that caregiving might have on caregivers working in AIDS care (Davids et al. 2009). Research in this area could not only provide a better understanding of caregivers' needs and their psychological well-being, but also highlight ways in which to better prevent occupational stress and burnout.

Since people spend a large proportion of their time at work, being fulfilled in one's occupation can greatly contribute to psychosocial well-being. However, some occupations are associated with higher levels of stress that can negatively impact on psychosocial well-being. Ryff (1989) defines psychosocial well-being as the development of a person's real potential. Along these 
lines happiness or psychosocial well-being is not the main motivation of the person, but rather the result of a well-lived life. This implies that the person will strive towards living a good life. Psychosocial well-being can generally be seen as an encompassing collective phrase for gratification, satisfaction with all aspects of life, accomplishment, peace and happiness (Ryff 1989). This implies that psychosocial well-being is closely linked to the absence of excessive stress (Davids et al. 2009). In the AIDS field, however, healthcare workers are faced with distinctive demands (for example, dealing with the social, mental, spiritual and physical problems experienced by people living with HIV infection) that may make them more prone to experience decreased psychosocial well-being and an increase in distress, feelings of not coping and burnout compared to workers in other areas (Davids et al. 2009). Several stressors inherent in AIDS care have been identified, such as frustration due to the overwhelming nature of the disease, bereavement overload, fear of social stigma and isolation, different types of patient-caregiver relationships, over-identification with patients, fear of contagion, and lack of social support (Delobelle et al. 2009; Miller et al. 2007; Mullins 2009; Van Dyk 2007).

Employees increasingly experience excessive stress at work, especially in the healthcare profession, and more so in developing countries and where resources are not readily available (Delobelle et al. 2009). Occupational stress is a common problem in everyday life and is a consequence of combined exposure to a multitude of factors in the work environment and employment conditions (Miller et al. 2007). In the healthcare profession workers often feel unable to cope with the responsibility for the health and well-being of other people (UNAIDS 2006). Occupational stress can be defined as the result of discrepancies between demands in the workplace and an individual's perceived ability to cope with or to meet these demands (Brant et al. 2010; Ogińskabulik 2006; World Health Organization [WHO] 2011).

Caregivers often experience feelings of inadequacy, helplessness, frustration and anger due to several organisational and infrastructural factors. These can impact negatively on the healthcare worker's psychosocial wellbeing if not resolved in a satisfactory manner (Delobelle et al. 2009; Mullins 2009; Van Dyk 2007). Some of the organisational challenges contributing to occupational stress or workplace-related stress include lack of space and privacy, insufficient organisational support and acknowledgement, heavy workload, inadequate training, insufficient funding, insufficient safety measures, and lack of medical supplies (Miller et al. 2007; Mullins 2009; Ogińska-Bulik 2006).

The stressors inherent in AIDS care and work-related stressors do indeed create a tense working environment (Fredriksen-Goldsen 2007; Van Dyk 2007). Ogińska-Bulik (2006) found that excessive stress led to various emotional and physical consequences for individuals, including somatic diseases, mental health disorders and feelings of exhaustion and burnout. Various researchers have reported on the physical effects of stress on caregivers, who complained of frequent headaches, muscle aches or general aches and pains, skin problems, change in appetite, insomnia, and inability to recover properly from colds and bronchial problems (Ogińska-Bulik 2006; Van Dyk 2012). These stressors can ultimately lead to burnout. Burnout refers to feelings of overstrain, tiredness, and fatigue resulting from long-term involvement in an overdemanding work situation (Fredriksen-Goldsen 2007; Ogińska-Bulik 2006). Burnout in the AIDS field can be defined as a psychological state of emotional exhaustion that results when the caregiver has reached his or her limit in dealing with persons with HIV infection and the accompanying emotional stress (UNAIDS 2006).

According to Maslach, Jackson and Leiter (1986) burnout syndrome is multidimensional and constitutes three elements, namely emotional exhaustion, depersonalisation, and diminished personal accomplishment. Emotional exhaustion refers to the sensation of both mental and physical wasting: the person feels that they have no energy and have reached their limit. Depersonalisation indicates a change in the caregiver's personality: he or she begins to have cold and impersonal contact with the people they are caring for, and eventually displays attitudes of cynicism, irony and indifference to others. This could result in caregivers treating patients as objects, being withdrawn from them and being judgemental, resulting in a strained patientcaregiver relationship. Diminished personal accomplishment is a feeling of a reduced sense of personal accomplishment at work, and is accompanied by feelings of inefficiency, low self-esteem, professional failure, demotivation, and an occasional desire to leave their job (Maslach et al. 1986).

Benevides-Pereira and Das Neves Alves (2007) found that even when desirable personal characteristics such as altruism, idealism, and empathy are evident in caregivers, when affected by burnout they become formal, insensitive, and often sarcastic. Occupational stress and burnout cause immeasurable damage to individuals and workplaces alike.

Although studies (such as Chirwa et al. 2009; FredriksenGoldsen 2007; Ogińska-Bulik 2006; Van Dyk 2007) have shown dissatisfaction and dropout amongst AIDS care workers, caring for people living with HIV infection can provide significant satisfaction (Akintola 2008). Satisfaction takes the form of the caregiver's sense of doing a good deed, obtaining the patient's appreciation, or seeing improvement in the patient's condition (Moreno-Jiménez et al. 2006). Akintola (2008) investigated the positive gains in caregiving and found that many caregivers achieved self-growth as well as personal, emotional, and psychological development. He further found that inner strength and confidence were achieved by caregivers through the use of their skills and knowledge when caring for people living with HIV infection. Job satisfaction was high amongst this group of caregivers.

Job satisfaction pertains to how employees feel about their work environment and the various aspects of their 
employment (Chirwa et al. 2009). Such feelings could be favourable or unfavourable. Locke (as cited in Chirwa et al. 2009:1298) defined job satisfaction as 'a pleasurable or positive emotional state resulting from the appraisal of one's job experience'. Healthcare workers working with people living with HIV infection are more likely to provide better care to patients when they are satisfied with their work (Mullins 2009) and correctly equipped to deal with organisational challenges. It is also evident that adequate education and training contribute positively to job satisfaction (Fransman et al. 2000). The workplace is an important environment for promoting the health of workers.

Teaching caregivers effective coping strategies also protects against occupational stress and burnout. Lazarus and Folkman (1984:141) define coping as 'constantly changing cognitive and behavioural efforts to manage specific external and/or internal demands that are appraised as taxing or exceeding the resources of the person.' Thus coping includes any attempt or effort to manage stress, regardless of how effective it is. Two coping styles are investigated in this study. Emotion-focused strategies occur when an individual believes that nothing can be done to change the situation, and include techniques such as denial and avoidance (Lazarus \& Folkman 1984). Notwithstanding, emotion-focused efforts such as praying and letting off steam to other people can make an individual feel better about the situation. Problem-focused strategies include those actions taken to alleviate or resolve the stressor when an individual views a stressful situation as open to change. An example of this type of strategy is seeking more or new information.

The main purpose of this study was to investigate what impact caring for people living with HIV infection has on the psychosocial well-being of formal palliative caregivers working in the AIDS field. To provide a more comprehensive view of psychosocial well-being, this study also looked at the stressors inherent in AIDS care as well as work-related stressors, and the effects of stress on the caregiver, ranging from negative feelings to burnout. Factors which may relieve stress, such as a sense of personal accomplishment, job satisfaction, coping mechanisms and psychosocial and workplace support, were also examined. A further aim of the research was to make recommendations on how to improve the psychosocial well-being of palliative caregivers caring for people living with HIV infection.

\section{Research method and design}

To investigate the psychosocial well-being of formal palliative caregivers working in the AIDS field, an exploratory mixed-design study was conducted. The study design comprised a qualitative component, indepth interviews with caregivers, as well as a quantitative component in the form of structured questionnaires. A mixedmethod design was preferred for this study as it allowed for a link between qualitative and quantitative components.

\section{Procedure and sample}

A sample of convenience was used. Three palliative care organisations in KwaZulu-Natal, South Africa, were selected to participate in the study and permission to conduct the study was obtained from the relevant managers. Since KwaZulu-Natal has the highest incidence of people living with HIV infection, and the researcher is based there, it made sense to obtain a sample from this area. The criteria for selection of the organisations included the following: the organisation had to be accredited by the Hospice Palliative Care Association of South Africa, had to include formal caregivers, and caregivers had to have one-on-one contact with HIV-infected and/or -affected people. Similarly, criteria for selection as part of the study included working for a palliative care organisation (either full-time, parttime, being on a payroll or as a volunteer), working in the field of AIDS care, and working in the capacity of a formal caregiver. Suitable participants that met these criteria were identified with the manager's assistance by confirming that the criteria were met.

During a briefing session with participants the study was explained and a consent form was completed. Participants were informed of the nature of the research, their right to confidentiality, and their right to terminate their involvement in the study at any time. Some issues of confidentiality that were explained included assurance that participation was highly confidential and that tapes and questionnaires would be stored safely and be destroyed once the study was completed. Their names and other personal information would not be revealed under any circumstances. A suitable date and time was arranged to conduct the interview (qualitative component) and fill out the questionnaires (quantitative component). The participants were contacted telephonically a week before the interview as a reminder. Twenty eight formal caregivers working in different occupations were selected. The study was approved by the ethics committee of the Department of Psychology at the University of South Africa.

\section{Measuring instrument}

To achieve the aims of this study and investigate the psychosocial well-being of palliative caregivers the following methods and measuring instruments were used:

- A biographical questionnaire was used to obtain information from participants such as age, gender, ethnic group and marital status as well as occupational details such as type of occupation, payroll or volunteer, homebased care, centre-based care or both, and the number of patients seen.

- An in-depth interview was conducted to investigate wellbeing. Questions such as: Do you experience any stressful events and distressing feelings due to caring for people living with HIV? Please elaborate; Has taking care of someone with HIV infection affected your relationships with friends and family? How? In general, what makes you most sad or happy about the care you provide? And, 
do you receive help and support when dealing with these everyday problems of caregiving and from whom?

- Participants were given the opportunity to talk about the challenges inherent in AIDS care, workplace-related challenges, the effects of these challenges and stress on them, and the factors that relieve or manage their stress, and were asked to give their own recommendations for improvement.

- Two self-administered questionnaires were used to measure burnout and job stress and/or satisfaction. The Maslach Burnout Inventory (MBI) was used to measure burnout, specifically emotional exhaustion, depersonalisation, and personal accomplishment. The Hospital Consultants' Job Stress and Satisfaction Questionnaire (HCJSSQ) measured stressful aspects of the healthcare worker's occupation (such as feeling poorly managed and resourced), occupational stress, as well as job satisfaction.

\section{Data analysis}

The in-depth interviews were analysed using thematic analysis. To determine to what extent the questionnaires contribute to our understanding of the psychosocial wellbeing of the caregivers who participated in the in-depth interviews, the following statistical techniques were used: descriptive statistics (means and standard deviations), correlational statistics (on the Maslach scale) and nonparametric tests to assess differences between groups.

\section{In-depth interview}

The in-depth interview was analysed using Braun and Clark's (2006) six phases of thematic analysis. The tapes obtained from the interviews were manually transcribed into a Microsoft Word document. Each question for each participant was then recorded in separate documents. Initial codes were recorded against general ideas that had similarities. Codes were then collated as possible themes, which were then reviewed in relation to the coded extracts. The themes were then defined and named. Finally, common topics amongst the answers were grouped under main themes and subthemes where appropriate. For example, issues such as lack of space and privacy, lack of masks and gloves were grouped under 'protective gear', and being asked to do too many things at once was placed under 'organisational challenges'.

\section{Questionnaires}

The questionnaires were used to complement the information gathered from the qualitative study.

MBI: The MBI developed by Maslach in 1986, consisting of 22 items divided into three subscales (emotional exhaustion, depersonalisation, and personal accomplishment) was used in the current study (Maslach et al. 1986). Items were written in the form of statements about personal feelings or attitudes (e.g. 'I feel burned out from my work', 'I don't really care what happens to some patients') and answered in terms of the frequency as well as the intensity with which the respondent experienced these feelings (Maslach et al. 1986). Frequency was measured on a 7-point, fully anchored Likert-type scale ranging from 1 (never) to 7 (every day).

To obtain scoring for both the frequency scale ('How often do you feel emotionally drained?') and intensity scale ('How intense is this feeling?'), each item was rated on a 7-point scale. For the frequency scale a score of 1 (never) was the minimum score and 7 (every day) the maximum score. For the intensity scale scores of 1 and 2 (very mild or barely noticeable) were the minimum scores and of 6 and 7 (very strong or major) were the maximum scores. After reversing the scores for items 10 to 17 (personal accomplishment scale) the total score for the MBI frequency scale was calculated by adding up all the scores and dividing the total score by the number of items in the scale (22 in total). This makes it easier to interpret the scores of the total scale because it is back to the original scale used for each of the items (from 1 to 7) (Pallant 2011:85). A high mean score on the MBI scale corresponds to a higher degree of burnout experienced (Maslach et al. 1986). Total scores were also obtained for the three separate dimensions of the MBI, namely the emotional exhaustion scale, the depersonalisation scale and the personal accomplishment scale.

HCJSSQ: The HCJSSQ, developed in 1994 by Teasdale, Drew, Taylor and Ramirez and modified in 2002 was used in the current study (Teasdale et al. 2008). The HCJSSQ consists of questions relating to stressful aspects of work, satisfying aspects of work and an overall rating of stress and satisfaction.

Stressful aspects of work made up the first 36-item part of the questionnaire. The items were written in the form of statements about stressful aspects of work, for example 'Feeling under pressure to meet deadlines'. Participants rated these aspects in terms of the extent to which they contributed to stress. The scale ranged from 0 (not at all) to 3 (a lot). For the purpose of this study, the scale was used as a whole and not divided into the six subscales as done by the original authors due to the small sample size. The second part of the questionnaire relating to satisfying aspects of the job consisted of 22 items in the form of statements about the extent to which these items contributed to satisfaction in the workplace, for example 'Deriving intellectual stimulation from teaching others'. Participants rated the statements to the extent that these aspects contributed to their job satisfaction. The scale ranged from 0 (not at all) to 3 (a lot). For the purpose of this study this scale was also used as a whole and not divided into the three subscales as done by the original authors. In the third part of the questionnaire relating to overall rating of stress and satisfaction, participants were asked to rate their overall feelings about stressful and satisfying aspects of their job on a scale ranging 
from 0 (not at all stressful) to 4 (extremely stressful) and 0 (not at all satisfying) to 4 (extremely satisfying).

To score the HCJSSQ each item on the job stress and the job satisfaction scales was rated on a 4-point scale. A score of 0 (not at all) was the minimum score and 3 (a lot) the maximum score. The total scores of each scale were calculated by totalling the scores and dividing this score by the number of items in the scale (36 in the case of the job stress scale and 22 in the case of the job satisfaction scale) to return the score to its original form (between 0 and 4). A high score on the job stress scale indicates job stress, whilst a high score on the job satisfaction scale reflects a high level of job satisfaction experienced. The overall rating of the stress and satisfaction scale was scored by awarding a score of 0 for 'not at all stressful/satisfying' and a score of 3 for 'extremely stressful/satisfying'.

\section{Results}

\section{Demographic variables}

The three organisations involved in the study are referred to as organisation A, B and C to protect their identity. The average age of the sample was 45.7 years $(S D=15.5$; range 22-74 years). The majority of the participants were female $(85.7 \%)$, with $14.3 \%$ males. Race groups represented were Indian (53.6\%), black people (35.7\%), white people (7.1\%) and mixed race $(3.6 \%)$. The occupations of the sample comprised occupational therapists $(3.6 \%)$, physiotherapists $(3.6 \%)$, social workers $(7.1 \%)$, spiritual counsellors $(3.6 \%)$, medical doctors $(7.1 \%)$, ward attendants $(3.7 \%)$, nursing assistants $(10.7 \%)$, professional nurses $(32.1 \%)$ and caregivers $(28.6 \%)$. Table 1 provides more biographical information. There were no significant findings in terms of group differences on the MBI and HCJSSQ scales.

TABLE 1: Demographic characteristics of participants $(N=28)$.

\begin{tabular}{|c|c|c|}
\hline Demographic characteristics of participants & $\%$ & $N$ \\
\hline $\begin{array}{l}\text { Gender } \\
\text { Female } \\
\text { Male }\end{array}$ & $\begin{array}{l}85.7 \\
14.3\end{array}$ & $\begin{array}{l}24 \\
4\end{array}$ \\
\hline $\begin{array}{l}\text { Ethnic group } \\
\text { Black } \\
\text { White } \\
\text { Asian } \\
\text { Mixed race }\end{array}$ & $\begin{array}{l}32.1 \\
7.1 \\
57.1 \\
3.6\end{array}$ & $\begin{array}{l}9 \\
2 \\
16 \\
1\end{array}$ \\
\hline $\begin{array}{l}\text { Marital status } \\
\text { Married } \\
\text { Single } \\
\text { Divorced } \\
\text { Widowed }\end{array}$ & $\begin{array}{l}35.7 \\
42.9 \\
3.6 \\
17.9\end{array}$ & $\begin{array}{l}10 \\
12 \\
1 \\
5\end{array}$ \\
\hline $\begin{array}{l}\text { Occupation } \\
\text { Caregiver } \\
\text { Professional nurse } \\
\text { Nursing assistant } \\
\text { Ward attendant } \\
\text { Medical doctor } \\
\text { Spiritual counsellor } \\
\text { Social worker } \\
\text { Physiotherapist } \\
\text { Occupational therapist }\end{array}$ & $\begin{array}{l}28.6 \\
32.1 \\
10.7 \\
3.7 \\
7.1 \\
3.6 \\
7.1 \\
3.6 \\
3.6\end{array}$ & $\begin{array}{l}8 \\
9 \\
3 \\
1 \\
2 \\
1 \\
2 \\
1 \\
1\end{array}$ \\
\hline $\begin{array}{l}\text { Place of care } \\
\text { Centre-based } \\
\text { Home- and centre-based }\end{array}$ & $\begin{array}{l}25 \\
75\end{array}$ & $\begin{array}{l}7 \\
21\end{array}$ \\
\hline $\begin{array}{l}\text { Payroll and/or volunteer } \\
\text { Payroll } \\
\text { Volunteer }\end{array}$ & $\begin{array}{l}78.6 \\
21.4\end{array}$ & $\begin{array}{l}22 \\
6\end{array}$ \\
\hline $\begin{array}{l}\text { Frequency with which patient is seen } \\
\text { Daily } \\
\text { Weekly } \\
\text { Monthly }\end{array}$ & $\begin{array}{l}21.4 \\
39.3 \\
39.3\end{array}$ & $\begin{array}{l}6 \\
11 \\
11\end{array}$ \\
\hline
\end{tabular}

\section{In-depth interview}

The themes extracted from the interviews will be discussed in a manner that will reflect the main objectives of the study, namely in terms of the well-being of caregivers in general. More specifically, the stressors inherent in AIDS care and in the workplace, the effects of these stressors on caregivers and factors that might alleviate stress associated with working as a caregiver will also be discussed.

\section{Value of holistic AIDS care}

All of the participants in the current study indicated that the palliative approach to AIDS care had positively influenced their ability to care for people living with HIV infection as well as their personal approach to life. Early initiation of palliation played a vital role in caregivers' ability to cope with the disease, as expressed by a social worker who stated that when nothing more can be done, then the person must be made comfortable and allowed to die with dignity.

Whilst working within a holistic approach to care positively influenced caregivers' personal and professional lives, there were many factors inherent in AIDS care that impacted negatively on caregivers' everyday lives in the workplace. These factors are discussed next.

\section{Factors inherent in AIDS care}

AIDS is a chronic disease requiring care similar to other chronic diseases. However, there are significant differences in the management of AIDS that make care and support challenging. The following themes about factors inherent in AIDS care which made caring difficult were identified.

Suffering and dying: Constantly witnessing suffering and dying was a trigger for feelings of helplessness, frustration, and stress for caregivers in the current study. This was voiced by a physiotherapist: 'I don't deal with death and the suffering of my patients ... eventually I just break down and cry.'

Difficult patient-caregiver relationships: nly two caregivers encountered difficult relationships with patients, for example: 'You know sometimes the patients are very ill, sometimes they are very angry and they just scream at you for whatever they are feeling' (caregiver). Others told that their relationships with patients and the patient's family grew into meaningful and supportive ones. However, sometimes many caregivers found themselves getting too involved with the plight of a patient.

Over-involvement and identification: Caregivers in the current study seemed to over-identify with patients of a similar age or those with children of a similar age to their own, or who had similar life experiences. For example: 'When we going to lose a very young person, it affects us a lot because we have children of the same age and that really touches us' (ward attendant). Over-involvement and identification is often compounded by fear of being stigmatised for those working with the disease as well as those living with it. 
Stigma, secrecy, and lack of social support: The majority of caregivers in the current study feared being stigmatised, and kept the fact that they worked with people with HIV infection a secret from their family and friends. Only five caregivers who participated in this study shared their work experiences with family or friends. The majority felt that it was better to 'leave work at work' or that their significant others 'would not understand if they knew they worked with HIV' or that the nature of their job was 'just too complicated to burden their families or friends.'

Late initiation of treatment, support, and failure to adhere to ART: Caregivers in the current study often expressed feelings of helplessness, frustration and anger because their patient's treatment and support were not initiated timeously. Caregivers expressed frustration about patients starting ART too late, as follows: 'I think something could have been done earlier with regards to ART, etc.' (nurse). Another stress factor identified by caregivers was that patients did not adhere to their treatment.

Fear of contagion: Many caregivers in the current study said that they felt at risk of contracting HIV, tuberculosis (TB) and other HIV-related infections from their patients. The fear of contracting TB was much stronger in the current study, as explained by a nurse:

'With patients that have been on TB treatment together with ARVs [antiretrovirals] you often find they are declared over with their TB [cured]. But, they come back reinfected, and it's even worse because the medications don't even work ... because the strain of the virus [sic] is stronger. This is my biggest fear.' (nurse)

Caregivers working in AIDS care do indeed face many challenges and obstacles in the performance of their duties. These are distinct and sometimes unique challenges inherent in working with this disease that need to be acknowledged and addressed to prevent caregivers from experiencing occupational stress and eventual burnout. The next section is related to the factors inherent in AIDS care and explores work-related stressors.

\section{Work-related stressors}

Many caregivers indicated that AIDS care was not their personal choice, nor were they specifically trained in AIDS care. Some were 'forced' into the role; for others, AIDS care was added on over and above their normal duties. The following work-related stressors impacted on caregivers' day-to-day lives.

Lack of workplace support: Many caregivers felt that they were not appreciated or supported by their organisations, and did not have sufficient managerial support. This often affected their ability to do their jobs, as seen here: 'We want more help for us as carers, you know to be appreciated, to recognise that we need support and someone to talk to about how we feel' (caregiver). Caregivers felt unsupported and unappreciated when they had to perform these duties over and above their normal duties due to staff shortages.
Lack of staff: Several caregivers felt that they had a very heavy workload due to insufficient staff and that their jobs would be easier with more staff, as expressed by this nurse:

'It [more nurses] would cut down on my work because I have some teaching functions. I also visit the patients and when we do day-care; we go and give them lectures. I'm actively involved in short courses, which takes time to prepare. So it becomes quite a bit to deal with.' (nurse)

Heavy workload and role discomfort: Several caregivers were forced into doing jobs for which they were not fully equipped, which led to role discomfort. They expressed concern that it was not getting easier to cope with the workload: 'I find the workload seems to be getting heavier' (caregiver) and 'For me it's the sheer number of patients that are not well. So this does put a lot of strain on me, as I'm only one person, dealing with hundreds of patients' (medical doctor).

Lack of space and privacy: A few participants found it difficult to work with patients in limited space with almost no privacy. These caregivers often counselled patients in an open-plan hall or in any available room. There was often noise or disturbances from other patients and staff. For example:

'I see my patients in the day-care room [a small hall] and the usual programme is happening whilst I'm trying to talk to a patient. It is also a distraction and the patient finds it difficult to open up to me.' (Spiritual counsellor)

Need for education and ongoing training: The need for ongoing education and training in AIDS care at a staff and a managerial level on the holistic management of persons with HIV infection was identified, as explained by these caregivers: 'I think more training and education on HIV will be very beneficial for me' (nurse) and 'I feel management needs to be educated and trained with regard to palliative and AIDS care' (nurse).

Lack of transport and safety: Caregivers from organisations $\mathrm{A}$ and $\mathrm{B}$ who conducted home visits felt that transportation was a major problem, as it could not always be provided by the organisation. Some of the areas in which they conducted their visits were also not safe. Participants in organisation C used their own vehicles and the cost factor was a concern, as many patients lived far from the location of the organisation. Participants shared the following regarding transport and safety: 'Patients sometimes stay far away, so transport is the problem' (caregiver); 'I think the safety factor is worse. From where the clinic is based to where we go to the houses, is a notorious place for hijackings' (nurse).

Poor salary: One of the main concerns of caregivers in the current study was that their salaries were inadequate. The following comments made by some caregivers expressed the sentiments shared by most of the participants: 'It's really a meagre amount of money' (ward attendant) and 'I'm only disappointed by the salary' (nurse). 
Lack of government support: Participants cited lack of support from the government as a major concern and obstacle to holistic treatment and care for people living with HIV infection. For example, a medical doctor expressed her fear and frustration regarding lack of training and education of government- employed staff. She serviced government hospitals using palliation as her main approach to care, and often felt:

'... frightened to start a treatment, as I don't know if there's going to be some sort of backup or follow-up by the government doctors for example. I would definitely feel much better if I knew the government-employed staff were properly trained, educated, and kept up to date with new practice.' (Medical doctor)

\section{Effects of stress on caregivers}

Working with people living with HIV infection on a daily basis coupled with the stressors inherent in AIDS care as well as workplace-related problems can often have serious psychological effects on caregivers, leaving them feeling distressed, depressed, emotionally distant, and unable to cope (Fredriksen-Goldsen 2007; Van Dyk 2007). Some of the effects of stress on the caregiver are now discussed.

Emotional and physical toll of caregiving: Caregivers in the current study were very vocal about the emotional and physical effects that caring for AIDS patients had on them. Some of the effects of caregiving mentioned in the current study included the following: 'Sometimes it's very personal. It's death, and the way the disease eventually takes you, it's just so hard and upsetting' (nursing assistant) and 'Since I've been working here, my immune system is just shot and it's being around sick people. It takes months to shake the flu and bronchitis' (nurse).

Feelings of burnout: Some caregivers in this study expressed feeling burnt out by their jobs. Others shared their feelings of depersonalisation, emotional exhaustion and a diminished personal accomplishment, for example: 'I've gotten to the point where I'm doing the bare minimum rather than pushing myself like at the beginning of the year. I'm just getting a little uncaring and cold and I'm always exhausted' (occupational therapist). A medical doctor had this to share: 'There are times when I just shut off from my patients and sometimes it makes me want to say forget it I don't want to do this work. I feel completely exhausted, drained, and burnt out.'

\section{Factors relieving stress}

Despite many obstacles to care, the rewards of caregiving were highlighted by many participants as the main reason for staying in the occupation. Participants shared their experiences and details about the rewards of their jobs and the ways in which they relieved stress and coped with daily stressors.

Sense of personal accomplishment: Patient improvement and happiness was a motivation to many caregivers and offered them a sense of personal accomplishment. Some stayed in the occupation simply because they believed in helping other people and took comfort in the fact that they made a difference to the lives of their patients. For others seeing a smile on their patient's face through the hardest of times was enough to keep them going.

Job satisfaction: Participants in this study achieved job satisfaction in various ways. Feeling appreciated by patients and organisations was a motivation, as well as witnessing improvement in patients' conditions and effectively coping with stressful situations. For example: 'I think it's the way the patient just says thank you. ... The joy you get from them showing they appreciate you makes me happy. I know I'm helping someone else' (nurse). Job satisfaction was experienced by this doctor when patients experience a positive outcome, such as symptoms being effectively managed:

'When you get it right and communicate well to the family and there's a good outcome whatever that may be, it's the best feeling. Maybe it's just a good day or a patient is getting better, doing well, and symptoms being managed. That for me is a very happy day.'

Coping mechanisms used by caregivers: Coping mechanisms' effectiveness depends on how they assist caregivers to cope with their problems. However, sometimes coping mechanisms do not help and can have a negative effect on well-being. In the current study caregivers used both emotion-focused and problem-solving coping strategies. These coping mechanisms did help some caregivers to cope, but there were also instances where coping mechanism were ineffective.

A vast majority of caregivers said they used 'taking part in physical activities', 'praying', and 'asking for help', which are examples of active emotion-focused strategies to cope. Many caregivers also found that 'talking to other people' and 'trying to solve the problem' were the most beneficial ways of coping with their day-to-day problems; for example: 'If I have a problem, I go to the Sister and try to solve the problem. We will brainstorm until we find a solution that will work' (caregiver).

Some caregivers were inclined to use avoidant emotionfocused coping strategies that did not work, such as 'blaming someone else for the problem' or 'trying to forget about everything that was stressing them', 'going to sleep' or 'using drugs or alcohol' to relieve stress. Others did not have anyone to share their problems with, nor did they know how to find solutions to their problems. Many caregivers did not cope well and some even admitted that they did not cope at all when their patients died. A few caregivers relied more on ways of coping such as praying for the 'feeling to go away.' This resulted in them experiencing continuous strain.

\section{Questionnaires}

A discussion of the MBI and HCJSSQ scales follows. These were used to supplement the results obtained from the indepth interview. 


\section{$\mathrm{MBI}$}

The experience of burnout for the group as a whole $(n=28)$ on the total 22-item Maslach scale was as follows. The frequency with which the group experienced burnout was very low, with a mean of $2.07(S D=0.618)$. The minimum score was 1.14 whilst the maximum score was 3.27 (the range of the scale was from 1 (never) to 7 (everyday), with 7 indicating high levels of burnout). High scores thus indicated high levels of burnout. The intensity with which the group experienced burnout was also relatively low, with a mean of $2.98(\mathrm{SD}=0.780)$. The minimum score on the intensity scale was 1.55 , with a maximum score of 4.55 . It is clear from the results that the caregivers who participated in the study did not experience a high level of burnout in terms of frequency or intensity. See Table 2 for a summary of all of the scores.

Participants experienced low levels of emotional exhaustion and depersonalisation. Participants had a mean of 2.49 $(\mathrm{SD}=1.10 ; n=27)$ on frequency of experiencing emotional exhaustion, and a mean of $3.19(\mathrm{SD}=1.08 ; n=25)$ on intensity of emotional exhaustion. The minimum and maximum scores for emotional exhaustion were 1.0 and 4.56 for the frequency and 1.67 and 6.50 for the intensity of emotional exhaustion respectively. On depersonalisation, participants had a mean of 1.30 (SD = 0.53; $n=27$ ) on frequency of experiencing this. They experienced moderate levels of intensity of depersonalisation, with a mean of $3.89(\mathrm{SD}=1.72 ; n=9)$. The minimum and maximum scores for depersonalisation were 1.0 and 3.0 for the frequency and 2.0 and 7.0 for the intensity of depersonalisation respectively. Participants experienced a relatively high level of personal accomplishment, with a mean of $5.90(\mathrm{SD}=1.18 ; n=28)$ on frequency of experiencing this. They also experienced personal accomplishment with a relatively high intensity, with a mean of $5.18(\mathrm{SD}=1.14$; $n=27)$. The minimum and maximum scores for personal accomplishment were 1.0 and 7.0 for the frequency and 2.63 and 7.0 for the intensity of personal accomplishment respectively.

Correlations between Maslach subscales: The theoretical assumption that feelings of depersonalisation should be linked to the experience of emotional exhaustion was confirmed in the current study, but only for the intensity of these scales. There was a significant positive correlation between the intensity of depersonalisation and emotional exhaustion ( $r=0.775 ; p<0.05 ; n=9$; large effect size). This means that the more intensely a caregiver experienced emotional exhaustion, the more intense their feelings of depersonalisation were, and vice versa. Further, there was a significant positive correlation between the frequency and the intensity of experiencing emotional exhaustion $(r=0.619$; $p<0.01 ; n=24$; large effect size). There was also a significant positive correlation between the frequency and the intensity of experiencing personal accomplishment $(r=0.424 ; p<0.05$; $n=27$; medium effect size). This means that as the frequency of emotional exhaustion and personal accomplishment increase, so too does the intensity of these feelings (see Table 2 for results). The abovementioned finding is in agreement with theoretical expectations that these are separate, but related aspects of burnout (Maslach, Jackson \& Leiter 1986) (see Table 3).

\section{HCJSSQ}

The participants of the study experienced low levels of job stress, with a mean of $1.07(\mathrm{SD}=0.47 ; n=28)$ on the HCJSSQ (job stress) scale. The minimum score for the group (on a scale ranging from 0 to 3 ) was 0.03 , whilst the maximum score was 1.92. The stress level indicated on the overall stress rating scale was marginally higher, with a mean of 1.71 (SD $=0.60 ; n=28)$, minimum score 0 and maximum score 3 . With a combination of the two scales it can be concluded that the caregivers who participated in this study experienced low to moderate levels of stress. On satisfying items, participants were generally satisfied with their work. The mean for job satisfaction for this group was 1.91 ( $\mathrm{SD}=0.46 ; n=28)$, with a minimum of 0.46 and a maximum of 2.82 on a 0 to 3 scale. For the overall satisfaction rating scale a higher mean of 2.79 (SD $=0.42 ; n=28)$ was obtained, with a minimum score of 2 and a maximum score of 3 . The means on both scales indicate that the caregivers were very satisfied with their work.

Whilst job satisfaction was high amongst the caregivers in this study, other factors indicated that stress was prevalent in this group. Although the levels of stress were low to moderate, if not alleviated and effectively managed they could result in anxiety, helplessness, and feelings of not being able to cope, which ultimately can lead to burnout syndrome.

\section{Discussion}

Caregivers working in the AIDS field are subject to many stressors. Although caregivers are trained and supervised to a certain extent, little attention is given to how caring for people living with HIV infection impacts on caregivers' needs and psychosocial well-being. The psychological well-

TABLE 2: Means and standard deviations on Maslach scale.

\begin{tabular}{|c|c|c|c|c|c|}
\hline \multirow[t]{2}{*}{ Scale } & \multicolumn{5}{|c|}{ Means and standard deviations on Maslach scale (total and subscales) } \\
\hline & $N$ & Mean & Standard deviation & Minimum score & Maximum score \\
\hline Burnout (total scale): Frequency & 27 & 2.0724 & 0.61841 & 1.14 & 3.27 \\
\hline Burnout (total scale): Intensity & 27 & 2.9821 & 0.77959 & 1.55 & 4.55 \\
\hline Emotional exhaustion: Frequency & 27 & 2.4856 & 1.09525 & 1.00 & 4.56 \\
\hline Emotional exhaustion: Intensity & 25 & 3.1897 & 1.07954 & 1.67 & 6.50 \\
\hline Depersonalisation: Frequency & 27 & 1.2963 & 0.53312 & 1.00 & 3.00 \\
\hline Depersonalisation: Intensity & 9 & 3.8889 & 1.72401 & 2.00 & 7.00 \\
\hline Personal accomplishment: Frequency & 28 & 5.8973 & 1.17608 & 1.00 & 7.00 \\
\hline Personal accomplishment: Intensity & 27 & 5.1839 & 1.14113 & 2.63 & 7.00 \\
\hline
\end{tabular}


TABLE 3: Correlations between Maslach subscales.

\begin{tabular}{lllllll}
\hline $\begin{array}{l}\text { Spearman's rank-order } \\
\text { correlation } \\
\text { coefficient }\end{array}$ & $\begin{array}{l}\text { EE: } \\
\text { Freq }\end{array}$ & $\begin{array}{l}\text { PA: } \\
\text { Freq }\end{array}$ & $\begin{array}{l}\text { D: } \\
\text { Freq }\end{array}$ & $\begin{array}{l}\text { EE: } \\
\text { Intens }\end{array}$ & $\begin{array}{l}\text { D: } \\
\text { Intens }\end{array}$ & $\begin{array}{l}\text { PA: } \\
\text { Intens }\end{array}$ \\
\hline EE: Freq & & & & & & \\
Correlation Coefficient & 1.000 & 0.005 & 0.203 & 0.619 & 0.255 & -0.125 \\
Sig. (2-tailed) & - & 0.981 & 0.311 & $0.001^{* *}$ & 0.507 & 0.543 \\
$N$ & 27 & 27 & 27 & 24 & 9 & 26 \\
PA: Freq & & & & & & \\
Correlation Coefficient & 0.005 & 1.000 & -0.015 & 0.067 & 0.278 & 0.424 \\
Sig. (2-tailed) & 0.981 & - & 0.942 & 0.751 & 0.469 & $0.028^{*}$ \\
$N$ & 27 & 28 & 27 & 25 & 9 & 27 \\
D: Freq & & & & & & \\
Correlation Coefficient & 0.203 & -0.015 & 1.000 & 0.204 & 0.218 & -0.073 \\
Sig. (2-tailed) & 0.311 & 0.942 & - & 0.339 & 0.572 & 0.722 \\
$N$ & 27 & 27 & 27 & 24 & 9 & 26 \\
EE: Intensity & & & & & & \\
Correlation Coefficient & 0.619 & 0.067 & 0.204 & 1.000 & 0.775 & 0.184 \\
Sig. (2-tailed) & $0.001^{* *}$ & 0.751 & 0.339 & - & $0.014^{*}$ & 0.380 \\
$N$ & 24 & 25 & 24 & 25 & 9 & 25 \\
D: Intensity & & & & & & \\
Correlation Coefficient & 0.255 & 0.278 & 0.218 & 0.775 & 1.000 & -0.038 \\
Sig. (2-tailed) & 0.507 & 0.469 & 0.572 & $0.014^{*}$ & - & 0.922 \\
$N$ & 9 & 9 & 9 & 9 & 9 & 9 \\
\hline PA: Intensity & & & & & & \\
Correlation Coefficient & -0.125 & 0.424 & -0.073 & 0.184 & -0.038 & 1.000 \\
Sig. (2-tailed) & 0.543 & $0.028^{*}$ & 0.722 & 0.380 & 0.922 & - \\
$N$ & 26 & 27 & 26 & 25 & 9 & 27 \\
\hline & & & & & & \\
\hline
\end{tabular}

$\mathrm{EE}$, emotional exhaustion; $\mathrm{PA}$, personal accomplishment; $\mathrm{D}$, depersonalisation; Freq frequency; Intens, intensity; Sig, significance.

being of palliative caregivers is of great concern and needs urgent research attention as well as intervention to improve their overall well-being. Several stressors inherent in AIDS care were highlighted by caregivers in the current study. These stressors had a negative impact on caregivers' daily lives.

\section{Stressors inherent in AIDS care}

\section{'I can no longer stand the suffering and the dying'}

Caregivers in the current study indicated that they sometimes felt emotionally drained by their jobs. Death of the people for whom they cared was an especially difficult part of caregiving. The results of the current study indicated that witnessing suffering and dying influenced the emotional toll of caring and had a negative effect on the caregiver's wellbeing. These findings support the research of Delobelle et al. (2009), Miller et al. (2007), Mullins (2009) and Van Dyk (2007), who found that caregivers experienced feelings of distress, felt overworked, demoralised and emotionally distressed due to witnessing patients with an incurable disease deteriorate over a long period.

\section{'Relationships with patients can be complicated'}

Many studies have found that the relationship between caregivers and patients in AIDS care are unique in comparison with other chronic illnesses (Miller et al. 2007; Mullins 2009). These researchers maintain that due to the dynamics of HIV infection, these relationships are often stressed. Although the current results are not entirely consistent with the findings of these researchers, a few caregivers complained about some patients being stubborn, but they consistently aimed at winning the patient over. However, in trying to build good relationships with their patients some caregivers got too involved in the lives of their patients, which created problems with coping and complicated the relationships. This led to many of them feeling 'used up at the end of each day'. Some caregivers felt that their job was hardening them emotionally, which complicated relationships with patients even further. These findings were similar to those of Mullins (2009), who stated that over-involvement and identification is a significant contributor to job satisfaction and is a predictor of burnout.

\section{'I can't talk to them - they won't understand'}

Very few caregivers shared their experiences at work with their family and friends. The majority of the caregivers believed that they would be stigmatised and that their families and friends would not understand the dynamics of working with HIV-infected and affected people. They were afraid of being 'treated differently if they discussed their jobs with their family or friends and they would rather not have those hassles'. These feelings of not wanting to share work experiences with their family and friends, were also identified by Martin et al. (2004), who suggest that lack of social support may originate from working with a highly stigmatised disease, as well as from a hesitancy to share information about patients.

\section{'They are almost dead when they come to us'}

Late initiation of treatment, lack of support and failure to adhere to ART was a significant cause of stress to caregivers in the current study. Many caregivers felt powerless and angered due to patients' non-adherence to their medication prescription and eventually dying as a result; for example: 'She died. I'm just so angry that she did not comply and refused her medication.' The current study supported the findings of Mullins (2009) and Van Dyk (2010), who stressed that non-adherence to antiretroviral medications contributes significantly to caregivers' feelings of helplessness and having no control over the health of their patients.

\section{'Quietly inside me that fear is always there'}

Although most of the caregivers in the current study felt comfortable working with people living with HIV infection, many felt fearful of working with people with $\mathrm{TB}$, and that fear of being infected with TB made them feel uneasy and afraid, especially when patients came back reinfected with a stronger strain of TB. This finding was also emphasised by Beylis (cited in HIV and AIDS treatment in practice 2009), who explained that the risk of $\mathrm{TB}$ is much higher due to caregivers working so closely with infectious TB patients, especially if safety measures are not in place. However, the worries of caregivers in the current study were eased to a certain extent when they were given gloves and masks to protect themselves. 


\section{'I just can't shake this flu'}

Some common physical symptoms reported by caregivers who participated in the current study included reoccurring flu and bronchitis, loss of appetite, a change in sleep patterns, and frequent headaches. Many caregivers also felt fatigued when they got up in the morning and had to face another day at work. Most of the physical symptoms mentioned by Van Dyk (2012) in her research on the well-being of caregivers were also experienced by caregivers in the current study. This supports the finding that caring for people living with HIV infection often has a negative impact on caregivers' physical well-being.

The stressors inherent in AIDS care have a serious impact on caregivers' well-being if not recognised and effectively managed. Apart from dealing with these daily stressors, workplace- related stress can also have a negative impact on caregivers' well-being.

\section{Work-related stressors}

Organisations have a challenging task of looking after their caregivers, that is accompanied by many complications and unmet needs. For many reasons organisations cannot meet the needs of caregivers, and this often results in occupational stress. The following workplace stressors were identified in the current study.

\section{'We want more support for us as carers'}

Caregivers in the current study were outspoken about the lack of support and communication from the management of their organisations. Many caregivers expressed frustration with their job, and felt that they had insufficient input from their organisation. They felt unsupported and unappreciated when HIV duties were added onto their normal duties and whilst AIDS care was not part of their job description. Similar findings by Davids et al. (2009) highlighted the fact that brief talks with supervisors were not enough for participants in their study to share their problems, find solutions and talk about their concerns.

\section{'We need more staff ... I can't cope if I don't take work home or stay late'}

An onerous workload and the fact that they were moved around within the organisation because of staff shortages was of concern to many caregivers in the current study. This created an uneasy feeling on a day-to-day basis and had a negative impact on the well-being of caregivers. Delobelle et al. (2009) highlighted that insufficient staff in the AIDS field impacts negatively on the caregivers' ability to perform certain roles in the care of HIV-infected people. Lack of staff results in a heavy workload and role discomfort (Martin et al. 2004). Caregivers complained about a heavy workload and role discomfort due to staff shortages, being forced into doing jobs for which they were not adequately trained, uneasiness due to not being equipped to work with HIV, administrative workloads, and the increasing number of patients. The findings of Fransman et al. (2000) and Mullins
(2009) emphasised how the physical and emotional wellbeing of caregivers are affected by heavy workload and how this, alongside changing roles and role discomfort, can lead to caregiver burden.

\section{'I use whatever room is available to me ... I'm constantly disturbed'}

Having inadequate facilities in terms of both equipment and space to do their job properly was a concern expressed by many caregivers in the current study. Caregivers found it difficult to work with patients in a confined space and with almost no privacy. The findings of other studies such as those conducted by Delobelle et al. (2009) and Mullins (2009) agree that HIV treatment, therapy or counselling should be conducted in an environment that allows for privacy and confidentiality. Healthcare workers who participated in these studies often mentioned lack of space and privacy as impacting negatively on their ability to do their job properly.

\section{'I don't believe we are properly trained'}

Many caregivers in the current study felt that their basic training did not cover all the necessary aspects of HIV care and support, and that they needed more education on caring for people living with HIV infection as well as on how to care for themselves. A few caregivers also felt that they were not properly educated and trained on delivering holistic care to HIV-infected and -affected people. Mullins (2009) found that factors such as lack of education and training contributed to occupational stress.

\section{'We need transport to go door to door to see patients ... it's not safe'}

Transport and safety were a daily concern and source of stress to the majority of caregivers. A further concern was that many of the areas which they visited were not safe and were notorious high-crime areas. For others the cost factor was of concern as many home visits were conducted far from their place of work and at the personal expense of the caregiver. Home care is an important part of delivering treatment and services to HIV-infected people; however, many organisations do not realise the uneasiness that is caused due to inadequate access to transport (Fransman et al. 2000).

\section{'You will be shocked at how little it is'}

Poor salary was a prominent concern for the majority of caregivers in the current study. Caregivers felt that working in AIDS care had financially impacted on them personally. The vast majority of caregivers indicated that a better salary with benefits such as a petrol plan would not only alleviate some of the stress encountered by them but could also provide motivation for them to remain in the field of AIDS care. This finding was supported by Moreno-Jiménez et al. (2006).

\section{'The government hospitals must stop telling people to come back later'}

Factors such as lack of government support, inadequately trained government staff, and inadequate governmental systems for HIV healthcare impacted negatively on 
caregivers. Many caregivers in the current study felt that the government was not responding to HIV and AIDS with the urgency they believed was needed. Likewise, caregivers in Van Dyk's (2007) study expressed frustration with slow government action and misleading information about HIV and AIDS.

\section{Factors impacting positively on the well-being}

Whilst caregiving in the AIDS field has its challenges and burdens, there are many satisfying and fulfilling aspects, as highlighted by the majority of caregivers in the current study. Examples of positive aspects of care identified in the current study are discussed below.

The holistic approach to care for people living with HIV infection proved to be an effective approach not only for patients but for caregivers providing the care and support. Caregivers expressed that palliative care had positively influenced their personal and professional lives, and allowed them to provide quality care to their patients. Working within multidisciplinary teams helped them deal with the many aspects of care and support for people living with HIV infection. This is in agreement with various other studies that found working within an interdisciplinary team assisted both caregivers and patients to cope with the impact of HIV and AIDS on their lives (Hospice Palliative Care Association of South Africa 2011; Van Dyk 2012; WHO 2011).

A sense of personal accomplishment can act as a barrier against the negative aspects of caregiving, providing a sense of self-worth as well as job confidence (Akintola 2008; Moreno-Jiménez et al. 2006). The majority of the caregivers felt that they were positively influencing the lives of others through their job, and that they could easily create a relaxed atmosphere with their patients and felt exhilarated after working closely with them. They remained in the AIDS field simply because of feelings of personal accomplishment in their jobs.

When caregivers are correctly equipped to deal with organisational challenges and satisfied with their work they are more likely to provide better patient care and cope better with stressful situations (Fransman et al. 2000). Appreciation by patients and organisations greatly impacted on job satisfaction and was an important predictor of job satisfaction in the current study. Another factor that contributed to job satisfaction was witnessing overall improvement in patients, which was closely monitored by caregivers. For example, they monitored their patient's CD4+ T-cell counts and felt joy when there was an improvement. The majority of caregivers felt that they were able to bring about positive change in their unit and/or institute and that having opportunities for personal learning (developing clinical/research/management skills) contributed to job satisfaction. Having the ability to make a difference, the opportunity to learn and develop their skills and derive intellectual stimulation from their jobs also impacted positively on the experience of job satisfaction for caregivers in the current study.

\section{Coping mechanisms}

The effective use of coping strategies plays an important role in the management of occupational stress. Caregivers in the current study successfully used active emotionfocused strategies and/or avoidant emotion-focused coping strategies. Examples of active emotion-focused strategies used by caregivers in the current study included 'taking part in physical activities' and 'asking for help', which alleviated stress, even though the problem was not solved. When a situation cannot be changed, caregivers often use avoidant emotion-focused coping strategies in such a creative way that they actually help them to cope effectively with their stress. For example: 'I have two bags, my home bag and my work bag. When I come to work, I pick up my work bag. When I go home, I leave the work bag and I pick up my home bag, and I go home. I've separated it.' Although this caregiver avoided talking to her family about her problems at work, she managed to cope by separating her work life from her home life. The majority of caregivers who participated in the current study also used problem-focused coping strategies and found that 'talking to other people' and 'trying to solve the problem' were the most beneficial ways of coping with their day-to-day problems. Some caregivers actively got together and tried to find solutions to various problems they encountered.

Some caregivers, however, used coping mechanisms which did not help. For example, those who were more inclined to use avoidant emotion-focused coping strategies that did not work did not cope well, had a negative impact on their well-being and resulted in continuous strain. Despite numerous negative aspects of caring for people living with HIV infection, caregivers in the current study highlighted many positive aspects of care.

\section{Limitations of the study}

A sample of convenience was used which relied on identification of potential participants with the assistance of the organisations. This could bias the sample toward those participants who were more motivated to join the research and those that management favoured for the research. There is also a possible lack of diversity amongst the study participants across race, age and gender. A further limitation relates to small sample size $(n=28)$. Future research should include a larger sample size over a larger geographic area. A larger sample size may offer a sample with a broader range of demographic data, which may in turn produce a more diverse sample. This could increase the statistical power of the study and improve the reliability, validity, and generalisation of research findings.

\section{Recommendations}

Effectively managing occupational stress is a crucial means of ensuring that caregivers do not head towards burnout. Recognising that caregivers in the AIDS field need support for themselves and from their organisations will 
be a significant means of combating the negative effects of caring. Recommendations for caregivers, organisations, and government will now be provided.

On an individual level, caregivers need to make their feelings and needs known by actively voicing how they feel. Ensuring that caregivers take short breaks during the day can help them manage stress on a daily basis. Caregivers should also make a concerted effort to separate their personal lives from their professional lives, which will help them keep their work-related stress away from their home life.

Organisations can support their caregivers in the following ways to alleviate stress: by appointing more staff to reduce the heavy workload, providing ongoing in-service training and education, finding ways of getting around transport issues, facilitating privacy when working with patients, revising the allocation of resources, and providing a better salary or incentives. Until more staff can be hired, it is suggested that staff be rotated to incorporate less stressful aspects of work such as organising fundraisers, or be rotated to do jobs not related to HIV infection.

It is suggested that organisations that do not have any support policies for their caregivers look into sending their staff on training programmes. They can also appoint mentors with counselling skills who can be responsible for the emotional and psychological welfare of their caregivers. It is also recommended that caregivers be debriefed after a stressful experience. Peer education is particularly effective in bringing about continuous knowledge, attitude change and coping skills. Regarding problems with transport to conduct home visits, a car pool system could help alleviate this. Organisations can ensure that caregivers are not disturbed when busy with patients by allocating a room specifically for counselling of patients. Organisations can appoint someone within the organisation to deal specifically with prioritising purchasing of resources such as gloves, as well as compiling motivations to potential funders.

A further suggestion is that the government provide trained counsellors for their staff and adequate education and training on the holistic management of AIDS care. The government would need to look into a more efficient system of starting patients on ART as soon as possible, to sustain treatment and to assist patients to adhere to their regimens.

\section{Conclusion}

The main aim of this study was to investigate the psychosocial well-being of formal palliative caregivers working in the AIDS field. Many findings of the current study supported findings of previous studies with regard to the stressors inherent in AIDS care, the effects of stress on the caregiver, and the factors which may relieve these stressors. These factors ultimately impact on the psychosocial wellbeing of caregivers working in the field of AIDS care. The findings of this study were not intended for generalisation to others, but they do add contextual depth to the meaning of caregiving for this sample and the impact it has on psychosocial well-being.

In essence, the findings of this exploratory study provide a better understanding of the participants' unique caregiving experiences. The in-depth interview particularly provided very touching and rich details about the participants' relationships and feelings. In conclusion, as much as this study provides some new information and is in agreement with several other studies, it also posits further questions for future research. Future studies should consider minimising the limitations presented above and investigating the various stressors and obstacles highlighted in this study.

\section{Acknowledgements}

\section{Competing interests}

The authors declare that they have no financial or personal relationship(s) that may have inappropriately influenced them in writing this article.

\section{Authors' contributions}

L.V. (University of South Africa) and A.C.v.D. (University of South Africa) equally contributed to the research and writing of this article.

\section{References}

Akintola, O., 2008, 'Defying all odds: Coping with the challenges of volunteer caregiving for patients with AIDS in South Africa', Journal of Advanced Nursing 63(4), 357-365. http://dx.doi.org/10.1111/j.1365-2648.2008.04704.x

Benevides-Pereira, A.M. \& Das Neves Alves, R., 2007, 'A study on burnout syndrome in healthcare providers to people living with HIV', AIDS Care 19(4), 565-571. http://dx.doi.org/10.1080/09540120600722775

Brant, H., Wetherell, M.A., Lightman, S., Crown, A. \& Vedhara, K., 2010, 'An exploration into physiological and self-report measures of stress in pre-registration doctors at the beginning and end of a clinical rotation" International Journal on the Biology of Stress 13(2), 155-162. http://dx.doi. org $/ 10.3109 / 10253890903093778$

Braun, V. \& Clark, V., 2006, 'Using thematic analysis in psychology', Qualitative Research in Psychology 3, 77-101. http://dx.doi.org/10.1191/1478088706qp063oa

Chirwa, M.L., Greeff, M., Kohi, T.W., Naidoo, J.R., Makoae, L.N., Dlamini, P.S et al., , 2009, 'HIV stigma and nurse job satisfaction in five African countries', Journal of the Association of Nurses in AIDS Care 20 (1), 14-21. http://dx.doi. org/10.1016/j.jana.2008.10.001

Davids, A., Setswe, G., Lewa, N., Majaja, M., Naidoo, Y. \& Clayton, J., 2009, 'Community home-based carers: voicing their needs, voicing their challenges!', poster presented at the AIDS Impact Conference, Gaborone, Botswana, 22-25th September.

Delobelle, P., Rawlinson, J.L., Ntuli, S., Malatsi, I., Decock, R. \& Depoorter, A.M., 2009, 'HIV/AIDS knowledge, attitudes, practices and perceptions of rural nurses in South Africa', Journal of Advanced Nursing 65(5), 1061-1073. http://dx.doi. org/10.1111/j.1365-2648.2009.04973.x

Fransman, D., McCulloch, M., Lavies, D. \& Hussey, G., 2000, 'Doctors' attitudes to the care of children with HIV in South Africa', AIDS Care 12(1), 89-96. http:// dx.doi.org/10.1080/09540120047503

Fredriksen-Goldsen, K.I., 2007, 'HIV/AIDS caregiving: Predictors of well-being and distress', Journal of Gay and Lesbian Social Services 8(3), 53-73. http://dx.doi. org/10.1300/J041v18n03_04

HIV and AIDS treatment in practice, 2009, Caring for caregivers in the face of HIV and $T B$, viewed 06 June 2013, from http://www.AIDSmap.com

Hospice Palliative Care Association of South Africa, 2011, Caring for the Caring for the Caregiver, Open Society Foundation for South Africa, Durban.

Joint United Nations Programme on HIV/AIDS, 2006, Report on the Global AIDS Epidemic,Joint United Nations Programme on HIV/AIDS, Geneva.

Lazarus, R.S. \& Folkman, S., 1984, Stress, appraisal and coping, Springer, New York.

Martin, S.C., Wolters, P.L., Klaas, P.A., Perez, L. \& Wood, I.V., 2004, 'Coping styles among families of children with HIV infection', AIDS Care 16(3), 283-292. http:// dx.doi.org/10.1080/09540120410001665295 
Maslach, C., Jackson, S.E. \& Leiter, M.P., 1986, Maslach burnout inventory manual, Consulting Psychologists Press, Palo Alto, CA.

Miller, I.W., Bishop, D.S., Herman, D.S. \& Stein, M.D., 2007, 'Relationship quality among HIV patients and their caregivers', AIDS Care 19(2), 203-211. http://dx.doi. org/10.1080/09540120600624278

Moreno-Jiménez, B., Rodríguez-Carvajal, R., Furlong, L., Hernández, E. \& Benadero, M.E., 2006, 'Burnout process and HIV/AIDS: Main implications for health care workers', Revista Colombiana de Psicología 31(3), 67-80.

Mullins, I.L., 2009, 'How caring for persons with HIV/AIDS affects rura nurses', Issues in Mental Health Nursing 30, 311-319. http://dx.doi. org/10.1080/01612840902754461

Ogińska-Bulik, N., 2006, 'Occupational stress and its consequences in healthcare professionals: The role of type D personality', International Journal of Occupational Medicine and Environmental Health 19(2), 113-122. http://dx.doi.org/10.2478/ v10001-006-0016-7

Pallant, J., 2011, SPSS survival manual. A step by step guide to data analysis using SPSS, 4th ed., Open University Press, Berkshire, England.
Ryff, C.D., 1989, 'Happiness is everything or is it? Explorations on the meaning of psychological well-being', Journal of Personality and Social Psychology 57, 1069-1081. http://dx.doi.org/10.1037/0022-3514.57.6.1069

Teasdale, E., Drew, S., Taylor, C. \& Ramirez, A., 2008, The Hospital Consultants' Job Stress and Satisfaction Questionnaire (HCJSSQ). User Manual, pp. 1-26, London Cancer Research UK Psychosocial Group.

Van Dyk, A., 2007, 'Occupational stress experienced by caregivers working in the HIV/ AIDS field in South Africa', African Journal of AIDS Research 6(1), 49-66. http:// dx.doi.org/10.2989/16085900709490399

Van Dyk, A., 2010, 'Treatment adherence following national antiretroviral rollout in South Africa', African Journal of AIDS Research 9(3), 235-247. http://dx.doi.org /10.2989/16085906.2010.530177

Van Dyk, A., 2012, HIV/AIDS education, care \& counselling. A multidisciplinary approach, 5th edn., Pearson Education, Cape Town.

World Health Organization, 2011, New psychological first aid guide to strengthen humanitarian relief, World Health Organization, Geneva. 